\title{
DESCRIPTION OF AN IMPROVED WATER METER.
}

The important uses to which a correct and durable water meter might with great advantage be applied have been highly appreciated and extensively felt by practical men, more especially in the case of water works in large cities and towns, where an unlimited supply to the inhabitants could not be kept up, on account of the injudicious use and waste which wounld thereby ensue. When the source of supply is limited or insufficient, great care is requisite to make the means suit the end; and the supply can therefore be let on only at intervals, during which the consumers have to draw as much as they require until the time of next supply. Even this system however is attended with more waste than there would be, if people were to pay for all that they draw. The question of constant supply bas been entertained and considered in official quarters, but one great obstacle to its adoption, that has been reported, is the want of a thoroughly efficient meter.

The present policy of water companies is a fixed rate on rental, in the case of water supplied for domestic purposes; and a rate agreed upon by special contract according to the quantity supplied, in the case of water used for manufacturing and all other purposes. Hence, even under these arrangements, there is great room for the use of meters, it being most essential with large consumers to have a proper means of ascertaining the quantity supplied, which otherwise becomes a source of endless dispute and difficulty. Some companies fix a rate according to the size of service pipe, which may then run during day and night, whereas the supply wanted may be only partial, thereby entailing a very unequal rate, or great inconvenience and expense in erecting large cisterns.

The subject being thus one of general importance, many attempts have been made to produce an instrument capable of fulfilling the desired purposes. But it is remarkable that in this age of mechanical triumphs so many failures have occurred, and so much difficulty has been experienced in accomplishing what at first sight appeared such a simple matter. The non-elastic nature of the fluid, the impurities which generally exist in connection with a supply on an extensive seale, and the heavy pressure under a high column, were serious obstacles to the satisfactory working and durability of a machine intended to retain the pressure and to measure correctly. 
The first meters that were brought most generally into use were made on a variety of plans, but all requiring to be placed above a cistern, from which the water after measurement was drawn; this plan was however attended with many disadvantages.

It is unnecessary here to enumerate the various other plans resorted to in pursuit of the object referred to; it will be sufficient to notice the leading features of those at present most prominently in use. The several varieties of meters may be reduced to two distinct classes, according to the principle on which they work; the first class comprehending all meters that measure by the velocity at which the water flows; and the second class, those measuring by capacity.

Meters on the former plan are rotary, and are best constructed by placing a wheel, fan, spiral, or modification of revolving arms, on the principle of "Barker's Mill," in the water-course, so as to be propelled by the force of the water's motion, an indicator or counting apparatus being attached. This principle of action embraces a large number of inventions; but in the writer's opinion it does not admit of surmounting the difficulties of correct measurement under variable pressure and velocity, because the whole body of water in the chamber containing the working parts has to be put in motion with sufficient force to drive the rotating apparatus, before there can be any indication; and consequently small quantities of water can pass and be drawn off without registration. Another point of difficulty is to ensure a proper rate of rotation under a varying velocity of flow, in exact proportion to the quantity of water passing off. As regards durability and the confidence to be placed in continuous working and uniformity of registration, too much depends on the nice rotation of the mechanism; and this for the sake of sensibility to motion must be supported on centres which are liable to wear and allow of oscillation. Various causes may also increase the friction, or injure the revolving parts, so as to cause inaccuracy.

In the second class of meters, measurement by capacity is best effected by means of a cylinder and piston.

The meter described in the present paper is constructed on the principle of measurement by capacity, and is made with a cylinder and piston; it has been found to measure correctly and uniformly under every variation of pressure or velocity of flow. The water is discharged in a steady and 
continuous stream, without any shock, concussion, or intermission; the piston moves with grent ease, and is likely to be durable and easily kept in order.

The meter is shown in Figs. 1, 2, and 3, Plate 71.

Fig. $l$ is a side elevation of the meter, with the casing removed to show the internal mechanism, the measuring cylinder being in section.

Fig. 2 is a vertical section of the meter, and Fig. 3 a plan with the upper part of the casing removed.

The cylinder $A$ is fitted with a water tight piston $B$, the rod of which carries a rack $\mathrm{C}$, gearing into a pinion $\mathrm{D}$ connected with the counting apparatus. The water is admitted alternately above and below the piston by means of a fourway cock $\mathrm{E}$, which is reversed when the piston arrives at either end of the cylinder. The reversing is effected by a tumbler $\mathrm{F}$ falling over alternately upon two arms $G G$ on the spindle of the fourway cock $\mathrm{E}$, the tumbler being raised during each stroke of the piston by a stud or catch $\mathrm{H}$ fixed on the pinion $\mathrm{D}$.

The piston B is rendered water tight by a "rolling packing," consisting of a ring $I$ of vulcanised india rubber of circular section, which is drawn on the body of the piston like an india rubber band; in consequence of its elasticity the ring accommodates itself so completely to the space between the body of the piston and the cylinder as to make a water tight packing in a simple and effectual manner. The rolling action of the packing ring diminishes the friction, and consequently the liability to wear and tear, and the packing being impervious to water is not liable to rot or decay; this is one of the peculiarities of the meter, which is presumed to have overcome a material difficulty. It has been found from experience that no other packing would endure for a reasonable length of time; any other material which might be fitted water tight causes too much friction, and is liable to become leaky after wear; even the india rubber wonld be open to the same objection, were it not for its rolling action. It may be observed that the rolling packing, although admirably suited to the present purpose, would not be serviceable on a piston or plunger which had to meet much resistance, being efficient as a water tight packing only when exposed to nearly equal pressures on both sides, as in the present case, the piston merely floating in a current, and raising only the weight of the tumbler $\mathrm{F}$ by which the cock $\mathrm{E}$ is worked.

The cock or valve $\mathrm{E}$, shown in Figs. 4 and 5 , is so constructed as to leverse the water to opposite ports without the aid of an air vessel, causing 
not the slightest increase of friction, or any stoppage or check to the uniform flow of the water. The valve barrel is formed on the plan of a fourway cock, the key or plug being made more on the principle of a steam throttle valve; it does not completely cover the ports in crossing to reverse, but as the central position of the valve across the port is but momentary, the escape of water through the valve, which saves the recoil, is so inappreciable in quantity as not to cause a variation of one per cent. under the most extreme trial.

The tumbler or weighted lever $F$, which reverses the valve, is worked from the piston $\mathrm{B}$, the rod of which carries the toothed rack $\mathrm{C}$ in gear with the pinion $\mathrm{D}$; the shaft of the pinion is in the same line with the valve plug or key, on which is fixed a pair of bent lever arms GG, Fig. 5, placed for the tumbler $F$ to fall against on either side. During the stroke of the piston, the tumbler is raised up to a vertical position by means of a lifter or stud $H$ attached to the pinion $D$; but being loose on the shaft of the pinion, immediately on passing the centre it falls over by its own weight, striking the upraised arm of the valve $E$, which is instantly reversed. The water which has passed into the cylinder is then discharged by the return stroke of the piston, and the action continues in the same manner as in an ordinary high pressure steam engine. The tumbler is prevented from turning the valve too far over by a buffer $K$ suspended loose from the spindle of the pinion $\mathrm{D}$; the buffer receives the surplus force of the fall of the tumbler, and is limited to a small motion by the checks $L$; its resistance is increased by the friction of the guides $M$ between which it vibrates.

The indicating apparatus $\mathrm{N}$ is contrived to suit a variable flow of the water and its non-elastic condition, as it was found that the piston would not work to a definite length of stroke when the volume of flow varied. When the discharge was great the stroke was a little longer than with a small discharge; and to have made the piston work between checks, and count the strokes for indication, as has been done in other cylinder and piston meters, would not answer, because the actual distance travelled by the piston has to be measured, and the piston must have a free and independent action, and be allowed to float in accordance with the current; otherwise severe reaction, concussion, and derangement would be produced. Therefore to obtain accurate registration, the indicating apparatus $N$ is attached to the shaft of the pinion $D$, and made to move uniformly 
forward in one direction by means of a pair of ratchet wheels, while the piston traverses either upwards or downwards, giving always accurately the distance travelled by the piston; then the area of the cylinder being known, the indication of the quantity of water passed through must be correct, whether long or short strokes be made by the piston.

The amount of head pressure required to move and work this meter is very small, and would rarely be felt of any importance.

The meters for actual use are made so strong in all their parts as to stand the heaviest pressure in use in this country; they will work in any situation with complete freedom and accuracy, irrespective of the size, length, or distance of inlet or outlet pipes; and the meter may be placed on any part of the line of service pipe leading to the premises to be supplied. After passing through the meter, the outlet pipe may be branched in any direction, and the water drawn off in any quantity by as many outlets or cocks as may suit the convenience of the consumer; so that by the use of this meter the amount consumed is correctly registered, and no cistern is required where a constant supply can be obtained.

At the Nottingham Water Works one of these meters was tried, having the inlet pipe 100 feet long, upon which was fixed a pressure gauge, to detect shocks or variation of pressure. When at work the pressure at the meter ranged from 95 to 100 feet effective head, the total head being 130 feet; the discharge was 2000 gallons in $1 \frac{1}{4}$ hours, this quantity being afterwards measured and found to be quite correct. Though the trial was frequently repeated, no decided shock was perceived when the meter was at work.

At the Halifax Water Works a series of experiments was recently tried with one of the meters. A new meter was used with 1 inch outlet and inlet from a 2 inch main. The pressure upon the pipes was equal to a head of water 180 feet high. The test as to accuracy of measurement was made by filling from the delivery cock a standard gallon measure one hundred times. At the conclusion of the trial the meter registered 101 gallons, or 1 per cent. too much. On a second trial made in the same manner the result was 100 gallons exactly. To ascertain the loss of pressure sustained by the passage of water through the meter, a $\frac{1}{4}$ inch nib was placed upon the outlet, and played with a vertical jet in front of a measured surface; the water was then delivered 45 feet high. On discon- 
necting the meter, the same jet was found to deliver the water as nearly as possible to the same height as through the meter.

In reference to the practical application of these meters, a good example may be taken from the town of Preston, where they are extensively used by the corporation. In November 1854 one meter was sent there for trial, and approved of ; subsequently meters were put on all the large consumers, and now about 120 are in operation there. Previous to the use of the meters, the water was estimated at $9 \mathrm{~d}$. per 1000 gallons, but no satisfactory rule could be applied as to quantity; on application of the meters the rate was reduced to $6 \mathrm{~d}$. per 1000 gallons, and notwithstanding this reduction, a great increase was made to the revenue, and doubtless a vast saving in the waste of water. After twelve months' constant working of these meters, which had cost no expense from wear and tear, a number of them were again tested, and found to work as well and measure as accurately as when first put up.

The meters have also been used extensively for measuring the feed water supplied to steam boilers, and a considerable number have been applied for this purpose by the Government.

As regards the quantity which each size of meter would discharge, no definite rule can here be given; much depends on circumstances connected with the pressure and the pipes; but as a general rule, where a pipe of 1 inch bore will discharge from 10 to 35 gallons per minute, a 1 inch meter should be put on; but if by extraordinary pressure and freedom of delivery a 1 inch pipe would discharge a greater quantity, then a $1 \frac{1}{2}$ inch meter should be put on, and other sizes in the same proportion, no inaccuracy being produced by whatever size of pipe may be put to the meters, and the above restraint being recommended only so as not to overwork them. The sizes of meters at present made are $\frac{3}{8}, \frac{1}{2}, 1,1 \frac{1}{2}, 2,3,4$, and 5 inch inlet.

As regards the manufacture of the meters, it may well be supposed that the highest degree of perfection could not at first be attained; practical difficalties, which experience alone could show, interposed; the valve was placed too far from the cylinder, the ports were not wide enough, and the opposite currents meeting with too great velocity caused a shock; also the packing of the valve spindle gave some trouble. These difficulties have been most successfully overcome, and the meter has now attained such a state of completeness as it is hoped will satisfy the demands and conditions of a good water meter. 
Mr. Kennedy exhibited one of the meters in operation at different speeds, having a glass cylinder and casing, showing the action of the rolling packing of the piston and the tumbler and cock.

The Chairman enquired how many of the meters were now in use.

Mr. KENNEDY replied that about 1300 of the meters of various sizes were now at work.

Mr. Morr stated that he had been present at some of the experiments at Halifax, where different meters had been tried, but doubted the accuracy of the results, because the index was not fully graduated to show single gallons, and the exact quantity had been guessed at from larger divisions; he was satisfied however that the meter described registered correctly when in good order. He understood that one of the meters in use there had been found to stick from some sand getting in through the screen, and other meters had also stuck from other causes. He thought the meter involved a defect in principle, from the fact that if the tumbler from any cause stopped in its fall, it would either allow a continued delivery without registering, or would stop the supply of water altogether.

Mr. NeILson had tried a piston meter some 20 years ago, but had found a fatal difficulty in the leakage. Many attempts had also been made for several years, to construct water meters on the principle of the gas meter; but by this plan the pressure could not be communicated, and gas meters even could not be said to be perfect. The great difficulty in water meters arose from the variable pressures under which they were required to work, and he thought the eylinder meters, such as the present, were the best that were in use; he was much pleased with the rolling packing, which was certainly an ingenious and simple mode of preventing leakage with little friction. It was important to have as little machinery as possible in a water meter, and he thought the meter now described admitted of improvement in that respect.

Mr. KENNEDY considered that the rolling packing ring rendered the piston now perfect in respect of packing, and a pressure of only 18 inches head of water was required to work the piston including the tumbler; the piston was made of beech wood. Several meters were working on steam boilers at a factory at Leeds with good results, tending to prevent waste of fuel by showing the proportionate quantity of water evaporated in the boilers. The cost for repairs of a large number of meters at Preston had at present amounted to not more than $\mathfrak{3}$, and the charge for upholding 
the meters for 10 years was calculated at $2 \frac{1}{2}$ per cent. per annum on the original cost. He thought the cock would not be liable to stand across the port so as to leave it permanently open by any risk of the tumbler sticking in its fall, as had been supposed. The packing of the spindle of the cock had been a serious practical difficulty at first, but he had adopted now a good plan of packing, consisting of a small cupped leather; this had been found quite water tight and very durable, and gave little friction.

The Chatrman asked how the rolling packing ring was found to wear, and whether any of the rings had been worn out yet.

Mr. KENNEDY replied that none of the rings had been worn out yet, and the first which had been at work at Preston for two years appeared as good now as when put to work. The only cases of failure that he bad met with in the whole number at work were two instances where the ring had given way from a defect in the joint of the india rubber. Where a meter was employed to measure water in connection with a pump, as in supplying a boiler, every stroke of the pump caused a sudden oscillation in the stroke of the meter; but this was entirely prevented by placing a valve between the meter and the boiler, and the indication would then be given with great accuracy.

A vote of thanks was then passed to Mr. Kennedy for his paper and the working model exhibited.

The following Paper, by Mr. Edmund Hunt, of Glasgow, was then read :- 
PISTON WATER METER. Plate 71.
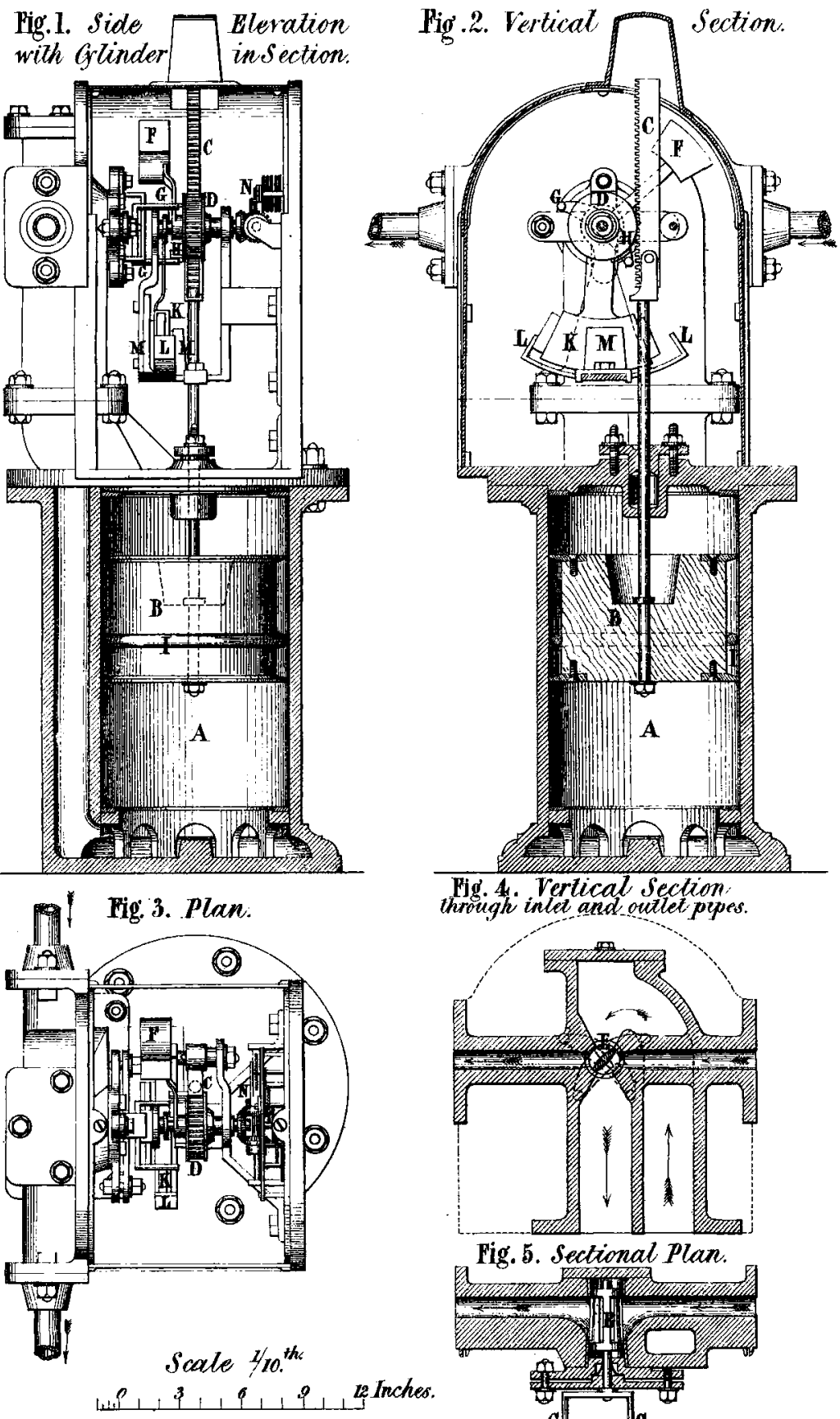

(Proceedings Inst. M.E. 18.56. Page 15.5.)

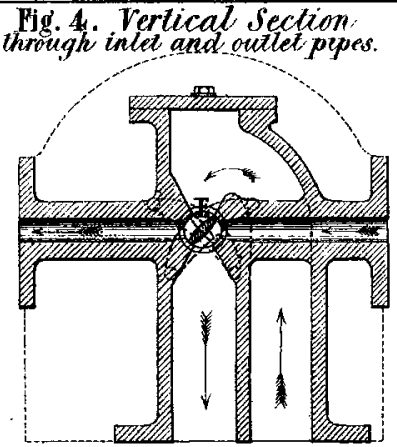

Fig. 5. Sectional Plan.

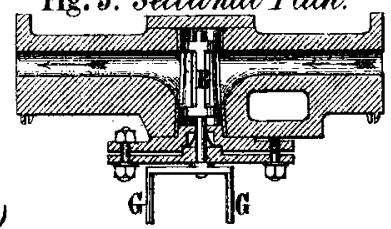

Downloaded from pme.sagepub.com at Gazi University on March 26, 2016 